Jurnal Teknik Komputer AMIK BSI

Volume 8, No.1, Januari 2022

P-ISSN 2442-2436, E-ISSN: 2550-0120

Akreditasi Ristekdikti, No: 36/E/KPT/2019 (Sinta 4)

DOI: $10.31294 /$ jtk.v4i2

\title{
Pemilihan Manager Keuangan Dengan Metode TOPSIS
}

\author{
Roy Andri ${ }^{1}$, Hardiyan ${ }^{2}$ \\ ${ }^{1}$ STMIK Nusa Mandiri \\ e-mail: royandripoerba61@gmail.com \\ ${ }^{2}$ Universitas Bina Sarana Informatika \\ e-mail: hardiyan.hry@bsi.ac.id
}

\begin{tabular}{ccc}
\hline Diterima & Direvisi & Disetujui \\
$15-10-2021$ & $28-12-2021$ & $11-01-2022$ \\
\hline
\end{tabular}

\begin{abstract}
Abstrak - Didalam suatu organisasi baik instansi atau perusahaan, terdapat seseorang yang mampu memimpin dan mengelola organisasi tersebut dengan baik, yang disebut dengan manager. Seorang manager membutuhkan kemampuan untuk mengarahkan orang lain dalam memberikan tugas dan tanggungjawabnya, sehingga diperlukan metode untuk mendapatkan manager yang tepat. Penelitian dilakukan di Batam Aero Technic, yang merupakan perusahaan di bidang penyedia layanan penerbangan yang dimana proses pemilihan manager masih hanya di lihat dari sebesar mana prestasi yang dihasilkan karyawan saja. Untuk mengatasi permasalahan tersebut maka peneliti menggunakan metode TOPSIS sebagai pendukung keputusan untuk menentukan manager keuangan pada Batam Aero Technic guna membantu proses pemilihan seorang manager keuangan dengan hasil yang akurat sehingga karyawan yang terpilih menjadi seorang manager yang layak.
\end{abstract}

Kata Kunci: Pendukung Keputusan, TOPSIS, Manager

Abstract - In an organization, whether an agency or company, there is someone who is able to lead and manage the organization well, which is called a manager. A manager needs the ability to direct others in assigning tasks and responsibilities, so a method is needed to find the right manager. The research was conducted at Batam Aero Technic, which is a company in the field of aviation service providers where the manager selection process is still only seen from the amount of achievements made by employees only. To overcome these problems, the researchers used the TOPSIS method as a decision supporter to determine the financial manager at Batam Aero Technic to assist the process of selecting a financial manager with accurate results so that the selected employee becomes a worthy manager.

Keywords: Decision Support, TOPSIS, Manager

\section{PENDAHULUAN}

Didalam suatu organisasi baik instansi atau perusahaan, terdapat seseorang yang mampu memimpin dan mengelola organisasi tersebut dengan baik, yang disebut dengan manager. Seorang manager membutuhkan kemampuan untuk mengarahkan orang lain dalam memberikan tugas dan tanggungjawabnya, sehingga diperlukan metode untuk mendapatkan manajer yang tepat. Jadi pada dasarnya pemilihan seorang manajer tidak boleh dipilih secara sembarangan berdasarkan hal yang dicapai saja terutama dalam memilih seorang manager di bagian keuangan, dalam memilih seorang manager keuangan harus bisa dilihat dari berbagai kriteria seperti memiliki sifat yang jujur, bertanggung jawab, memiliki pengalaman, memiliki pengetahuan yang luas, serta loyal terhadap perusahaan. Kualitas karyawan di sebagian besar perusahaan merupakan masalah yang sangat penting (Prihatin \& Retnasari, 2021).

Penelitian dilakukan di Batam Aero Technic, yang merupakan perusahaan di bidang penyedia layanan penerbangan yang dimana proses pemilihan manager masih hanya di lihat dari sebesar mana prestasi yang dihasilkan karyawan saja.

Didalam institusi atau perusahaan, kebijakan strategis dilakukan oleh seorang pemimpin, oleh karenanya harus sangat selektif dalam memilih pemimpin (Vikasari, 2018). TOPSIS adalah metode yang bersifat dinamis, dimana terdapat pemeringkatan dari yang tertinggi hingga terendah 
sebagai evaluasi peringkat (Budiman, Fauziah, \& Nathasia, 2020). Pengambilan keputusan dengan multikriteria atau alternative pilihan terdapat dalam metode TOPSIS (Muzakkir, 2017).

Untuk mengatasi permasalahan tersebut maka peneliti menggunakan metode TOPSIS untuk menentukan manajer keuangan pada Batam Aero Technic guna membantu proses pemilihan seorang manager keuangan dengan hasil yang akurat sehingga karyawan yang terpilih menjadi seorang manager yang layak.

\section{METODOLOGI PENELITIAN}

Dalam melakukan penelitian, yang perlu diperhatikan adalah tahapan-tahapannya. Berikut tahapan penelitian yang dilakukan:

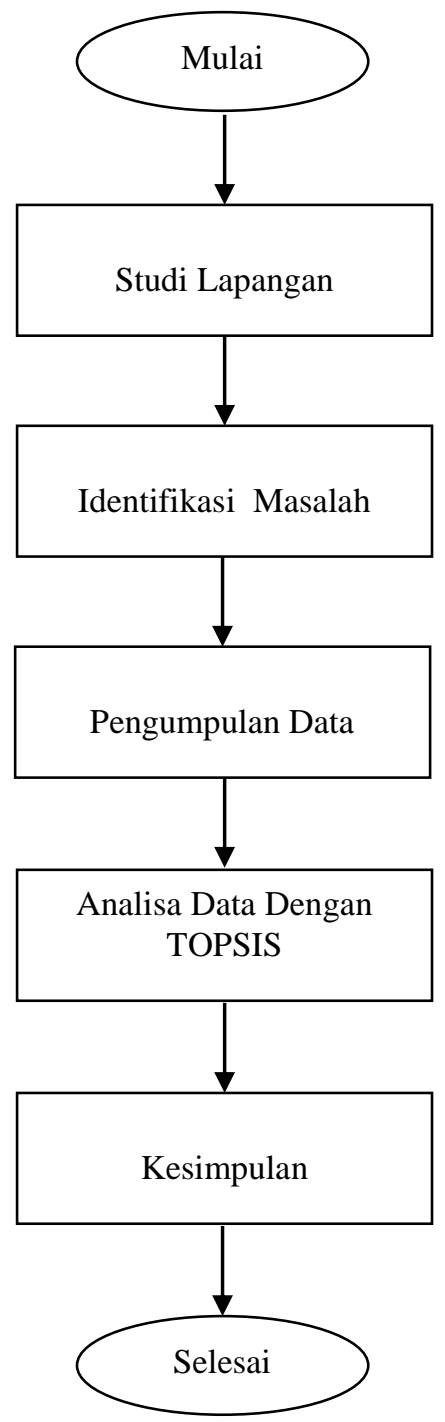

Sumber: Andri \& Hardiyan (2021)

Gambar 1. Flowchart Tahapan Penelitian

Ada lima tahapan dalam pelaksanaan penelitian yaitu :

1. Studi Lapangan
Melakukan studi lapangan berupa observasi untuk mengetahui permasalahan (Salsana, Simanjuntak, Naibaho, Simanjuntak, \& Siboro, 2021), yaitu perusahaan Batam Aero Technic.

2. Identifikasi Masalah

Melakukan pengidentifikasian masalah yang dari objek yang diobservasi, guna mencarikan data dan informasi keuangan pengangkatan karyawan manager.

3. Pengumpulan Data

Terdapat 4 (empat) dalam mengumpulkan data penelitian ini, antara lain: yang pertama observasi, kedua wawancara, ketiga studi kepustakaan dan yang terakhir koesioner. (Fridayanthie, Kusumaningrum, Haryanto, \& Setiawan, 2020).

4. Analisa Data dengan TOPSIS

Dari hasil pengumpulan data, dilakukan suatu analisa menggunakan metode TOPSIS sebagai dasar pertimbangannya. TOPSIS dinilai realistis, jika dibandingkan metode yang lainnya, yang mampu memilih alternatif terbaik (Santosa \& Sari, 2020).

5. Kesimpulan

Memberikan kesimpulan dari hasil perangkingan yang diperoleh dari hasil pengujian dengan menggunakan metode TOPSIS sebagai alat bantu dalam pengambilan keputusan.

Pada dasarnya metode analisis data dalam menentukan pengangkatan karyawan Batam AeroTechnic memiliki beberapa kriteria Sebagai berikut :

1. Absensi Kehadiran

Peneliti menggunakan absensi kehadiran sebagai salah satu kriteria pertama, untuk mengetahui apakah hipotesis absensi kehadiran mempunyai pengaruh dalam pengambilan keputusan pengangkatan karyawan. Dalam hal ini absensi kehadiran sangat berpengaruh terhadap penilaian dari pimpinan kepada karyawan dan salah satu syarat untuk pengangkatan manager keuangan

2. Kedisplinan

Peneliti menggunakan kedisplinan sebagai kriteria kedua, seperti yang diketahui kedispilnan karyawan sangat mempengaruhi pengambilan keputusan pengangkatan terhadap karyawan.

3. Wawasan Luas

Peneliti harus menggunakan wawasan yang luas kerjasebagai kriteria,karena seseorang calon manager keuangan harus mempunyai wawasan dan pengetahuan yang luas agar dapat tepat dalam mengambil keputusan.

4. Perilaku

Peneliti menggunakan perilaku sebagai kriteria keempat, perilaku yang baik mencerminkan bahawa seorang karyawan tersebut dapat 
bekerja dengan baik dan bertanggung jawab terhadap pekerjaannya.

5. Kejujuran

Peneliti menggunakan kejujuran sebagai kriteria ke lima karena seorang manager keuangan harus mempunyai sifat kejujuran yang sangat tinggi dalam mengatur keuangan perusahaan.

\section{HASIL DAN PEMBAHASAN}

Berikut merupakan kriteria yang telah ditentukan :

Tabel.1

Ketentuan Kriteria

\begin{tabular}{|c|c|}
\hline Kode & Kriteria \\
\hline $\mathrm{C} 1$ & Absensi Kehadiran \\
\hline $\mathrm{C} 2$ & Kedisplinan \\
\hline C3 & Wawasan Luas \\
\hline $\mathrm{C} 4$ & Perilaku \\
\hline $\mathrm{C} 5$ & Kejujuran \\
\hline
\end{tabular}

Sumber: Andri \& Hardiyan (2021)

Berikut nilai bobot yang ditentukan untuk setiap kriteria :

Tabel.2

Penentuan Nilai

\begin{tabular}{|c|c|}
\hline Kriteria & 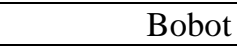 \\
\hline $\mathrm{C} 1$ & 5 \\
\hline $\mathrm{C} 2$ & 5 \\
\hline C3 & 4 \\
\hline $\mathrm{C} 4$ & 5 \\
\hline $\mathrm{C} 5$ & 5 \\
\hline
\end{tabular}

Sumber: Andri \& Hardiyan (2021)

Berikut merupakan table rangking kecocokan :

Tabel.3

Rangking Kecocokan

\begin{tabular}{ccccccc}
\hline NO & \multirow{2}{*}{ NAMA } & \multicolumn{5}{c}{ Kriteria } \\
\cline { 3 - 7 } & & C1 & C2 & C3 & C4 & C5 \\
\hline 1 & Reza & 5 & 3 & 4 & 4 & 3 \\
\hline 2 & Rudi & 4 & 4 & 3 & 3 & 3 \\
\hline 3 & Hasna & 5 & 3 & 5 & 5 & 3 \\
\hline 4 & Pipit & 3 & 3 & 2 & 3 & 3 \\
\hline 5 & Ari & 3 & 5 & 3 & 4 & 4 \\
\hline 6 & Rio & 4 & 5 & 3 & 3 & 5 \\
\hline
\end{tabular}

Sumber: Andri \& Hardiyan (2021)

\section{Membuat Keputusan Ternormalisasi}

$r i j=\frac{x i j}{\sqrt{\sum_{i=1}^{m} x_{i j}^{2}}}$

Berikut bentuk akar kuadrat dari kriteria1 adalah :

$$
=\sqrt{182}=13,49
$$

Tabel hasil normalisasi :

Tabel.4

Tabel Normalisasi

\begin{tabular}{ccccccc}
\hline NO & NAMA & \multicolumn{5}{c}{ Kriteria } \\
\hline & & C1 & C2 & C3 & C4 & C5 \\
\hline 1 & Reza & 0,37 & 0,25 & 0,34 & 0,34 & 0,27 \\
\hline 2 & Rudi & 0,30 & 0,33 & 0,25 & 0,25 & 0,27 \\
\hline 3 & Hasna & 0,37 & 0,25 & 0,42 & 0,42 & 0,27 \\
\hline 4 & Pipit & 0,22 & 0,25 & 0,17 & 0,25 & 0,27 \\
\hline 5 & Ari & 0,22 & 0,42 & 0,25 & 0,34 & 0,35 \\
\hline 6 & Rio & 0,30 & 0,42 & 0,25 & 0,25 & 0,44 \\
\hline 7 & Fera & 0,30 & 0,25 & 0,25 & 0,34 & 0,35 \\
\hline 8 & Atta & 0,37 & 0,25 & 0,25 & 0,25 & 0,35 \\
\hline 9 & Sony & 0,30 & 0,33 & 0,42 & 0,34 & 0,27 \\
\hline 10 & Neji & 0,37 & 0,33 & 0,42 & 0,34 & 0,27
\end{tabular}

Sumber: Andri \& Hardiyan (2021)

Tabel.5

Normalisasi Berbobot

\begin{tabular}{ccccccc}
\hline NO & NAMA & \multicolumn{5}{c}{ Kriteria } \\
\hline & & C1 & C2 & C3 & C4 & C5 \\
\hline 1 & Reza & 1,85 & 1,25 & 1,35 & 1,68 & 1,33 \\
\hline 2 & Rudi & 1,48 & 1,67 & 1,01 & 1,26 & 1,33 \\
\hline 3 & Hasna & 1,85 & 1,25 & 1,69 & 2,11 & 1,33 \\
\hline 4 & Pipit & 1,11 & 1,25 & 0,68 & 1,26 & 1,33 \\
\hline 5 & Ari & 1,11 & 2,09 & 1,01 & 1,68 & 1,77 \\
\hline 6 & Rio & 1,48 & 2,09 & 1,01 & 1,26 & 2,22 \\
\hline 7 & Fera & 1,48 & 1,25 & 1,01 & 1,68 & 1,77 \\
\hline 8 & Atta & 1,85 & 1,25 & 1,01 & 1,26 & 1,77 \\
\hline 9 & Sony & 1,48 & 1,67 & 1,69 & 1,68 & 1,33 \\
\hline 10 & Neji & 1,85 & 1,67 & 1,69 & 1,68 & 1,33 \\
\hline Sumber Andi & & &
\end{tabular}

Sumber: Andri \& Hardiyan (2021)

Tabel.6

Menghitung Jarak Alternative Ideal Positif dan Negative

\begin{tabular}{cccc}
\hline \multicolumn{2}{c}{$\begin{array}{c}\text { Jarak Alternatif } \\
\text { Ideal }+\end{array}$} & \multicolumn{2}{c}{$\begin{array}{c}\text { Jarak Alternatif } \\
\text { Ideal - }\end{array}$} \\
\hline D1+ & 1,33 & D1- & 1,09 \\
\hline D2+ & 1,51 & D2- & 0,65 \\
\hline D3+ & 1,22 & D3- & 1,51 \\
\hline D4+ & 1,94 & D4- & 0,00 \\
\hline D5+ & 1,18 & D5- & 1,09 \\
\hline D6+ & 1,14 & D6- & 1,32 \\
\hline D7+ & 1,29 & D7- & 0,79 \\
\hline D8+ & 1,44 & D8- & 0,93 \\
\hline D9+ & 1,13 & D9- & 1,23 \\
\hline D10+ & 1,07 & D10- & 1,39 \\
\hline
\end{tabular}

Sumber: Andri \& Hardiyan (2021)

Menghitung preferensi setiap alternatif

$X_{1}=\sqrt{5^{2}+4^{2}}+5^{2}+3^{2}+3^{2}+4^{2}+4^{2}+5^{2}+4^{2}+5^{2}$ 


$$
\begin{aligned}
V_{i} & =\frac{D_{1}^{-}}{D_{i}^{-}+D_{i}^{+}} \\
V_{1} & =\frac{1,09}{1,09+1,33} \\
V_{2} & =\frac{0,65}{0,65+1,51} \\
V_{3} & =\frac{1,51}{1,51+1,22} \\
V_{4} & =\frac{0,00}{0,00+1,94} \\
V_{5} & =\frac{1,09}{1,09+1,18} \\
V_{6} & =\frac{1,32}{1,32+1,14} \\
V_{7} & =\frac{0,79}{0,79+1,29} \\
V_{8} & =\frac{0,93}{0,93+1,44} \\
V_{9} & =\frac{1,23}{1,23+1,13} \\
V_{10} & =\frac{1,39}{1,39+1,07}
\end{aligned}
$$

Tabel.7

Nilai Preferensi untuk setiap alternative

\begin{tabular}{cc}
\hline Kode & Preferensi \\
\hline D1 & 0,45 \\
\hline D2 & 0,30 \\
\hline D3 & 0,55 \\
\hline D4 & 0,00 \\
\hline D5 & 0,48 \\
\hline D6 & 0,54 \\
\hline D7 & 0,38 \\
\hline D8 & 0,39 \\
\hline D9 & 0,52 \\
\hline D10 & 0,57 \\
\hline
\end{tabular}

Sumber: Andri \& Hardiyan (2021)

Nama Karyawan yang di rekomendasikan

Tabel.8

Hasil Perhitungan

\begin{tabular}{ccc}
\multicolumn{3}{c}{ Hasil Perhitungan } \\
\hline Kode & Nama & Preferensi \\
\hline D10 & Neji & 0,57 \\
\hline
\end{tabular}

Sumber: Andri \& Hardiyan (2021)

\section{KESIMPULAN}

Berdasarkan hasil penelitian yang penulis dapatkan maka dapat disumpulkan sebagai berikut:

1.Metode Technique for Order Preference by

Similarity to Ideal Solution (TOPSIS) pada penelitian ini digunakan sebagai alat bantu pendukung keputusan dalam pemilihan manager bagian keuangan pada Batam Aero Technic.

2.Penerapan metode TOPSIS dapat memberikan keputusan yang tepat dalam menentukan pemilihan manager bagian keuangan dengan kriteria yang sudah ditetapkan yaitu Absen kehadiran, Kedisplinan, wawasan luas, kejujuran dan perilaku.

3.Hasil perankingan yang diperoleh dari pengujian perhitungan bahwa alternatif D10 merupakan hasil perangkingan terbaik dengan hasil perhitungan 0,57 jika dibandingkan dengan kesembilan alternatif lainnya.

\section{REFERENSI}

Budiman, I. M., Fauziah, \& Nathasia, N. D. (2020). Sistem Pendukung Keputusan Pemilihan Karyawan Tata Usaha Biro Administrasi Universitas Nasional Menggunakan Metode SAW Dan TOPSIS. Jurnal Ilmiah Teknologi Dan Rekayasa, 25(2).

Fridayanthie, E. W., Kusumaningrum, A., Haryanto, \& Setiawan, F. A. (2020). Sistem Pendukung Keputusan Pemilihan Karyawan Terbaik Menggunakan Metode Topsis Pada PT Semangat Sejahtera Bersama. Jurnal Swabumi, 8(2), 171-176.

Muzakkir, I. (2017). Penerapan Metode Topsis Untuk Sistem Pendukung Keputusan Penentuan Keluarga Miskin Pada Desa Panca Karsa II. Jurnal Ilmiah ILKOM, 9(3), 274281.

Prihatin, T., \& Retnasari, T. (2021). Implementasi Metode TOPSIS Dalam Sistem Keputusan Penentuan Karyawan Terbaik. Jurmal Teknika, 15(01), 13-21.

Salsana, B., Simanjuntak, A., Naibaho, S., Simanjuntak, D., \& Siboro, B. A. H. (2021). Penerapan Metode SAW dan TOPSIS untuk Pemilihan Vendor Menempah Produk Marble. Jurnal Teknik Industri, 11(1), 30-36.

Santosa, T. I., \& Sari, R. (2020). Sistem Pendukung Keputusan Pemilihan Media Pembelajaran Online Menggunakan Metode TOPSIS. Riset Dan E-Jurnal Manajemen Informatika Komputer, 5(1), 69-75.

Vikasari, C. (2018). Sistem Pendukung Keputusan Pemilihan Direktur Politeknik Negeri Cilacap. Jurnal Edukasi Dan Penelitian Informatika (JEPIN), 4(2), 119 